\title{
Pro-Environment Being and Ecological Attachments
}

\author{
Juneman Abraham ${ }^{1}$, Any Rufaedah² \\ 1 Psychology Department, Faculty of Humanities, \\ Bina Nusantara University, Jakarta, 11480, Indonesia. \\ 2 Islamic Education Department, \\ Sekolah Tinggi Agama Islam Nahdlatul Ulama, Jakarta, 10430, Indonesia. \\ juneman@binus.ac.id
}

\begin{abstract}
This research related five attachment objects altogether, i.e. home attachment, neighborhood cohesion, workplace/campus attachment, city attachment, and national identity, with general pro-environmental behavior. Additional analysis included prejudice toward pro-environmental activists and psycho-sociodemographic profiles as explanatory variables. The participants were 262 urban young adults (121 males, 141 females; $M_{\text {age }}=30.09$ years, $S D_{\text {age }}=9.82$ years) who are citizens of Jakarta and its surrounding areas. The result showed that the higher the attachment to, consecutively, workplace/campus, city, and neighborhood, the higher the general pro-environmental behavior. Home attachment, national identity, and prejudice toward pro-environmental activists could not predict proenvironmental behavior.
\end{abstract}

Keywords: pro-environment; community; attachment; urban psychology

eISSN 2398-4295 @ 2018. The Authors. Published for AMER ABRA cE-Bs by e-International Publishing House, Ltd., UK. This is an open-access article under the CC BY-NC-ND license (http://creativecommons.org/licenses/bync-nd/4.0/). Peer-review under responsibility of AMER (Association of Malaysian Environment-Behaviour Researchers), ABRA (Association of Behavioural Researchers on Asians) and cE-Bs (Centre for EnvironmentBehaviour Studies), Faculty of Architecture, Planning \& Surveying, Universiti Teknologi MARA, Malaysia.

DOI: http://dx.doi.org/10.21834/ajbes.v3i10.86 


\subsection{Introduction}

Place attachment is "a positive affective bond between an individual and a specific place" (Hidalgo \& Hernández, 2001, p. 274). Scannell and Gifford (2010) divided place attachment into two types; those are natural/physical attachment and civic/symbolic/social attachment. They found that a natural attachment can predict pro-environmental behavior; on the other hand, a civic attachment cannot predict it. This present research is different from Scannel and Gifford's research since it assumes that based on Gestalt perspective (e.g., Winter \& Koger, 2004), both of the natural and civic attachment cannot be separated. For example, when people use the word "city" or "nation", those two words have already contained an abstraction or an imagination of a territorial, physical atmosphere, historical and futuristsymbolic-sociocultural dimension, and even the spirituality of the city or nation.

According to the author, the useful matter to be a focus for research is not the distinction between civic and natural attachment, but the effect of micro-, meso-, and macroattachments on pro-environmental behavior. Theoretically, someresearches (e.g., Dallago et al., 2009) have connected place attachment with social capital. On the other hand, social capital "exists at micro-, meso- and macro-levels, and may consist of horizontal as well as vertical relationships, or links of bonding, bridging or linking" (Francis, 2002, p. 5). By integrating the assumption with the findings of environmental psychology research, the author hypothesizes that multi-faceted attachments contribute to pro- environmental behavior. The empirical studies on this subject nevertheless were still inconclusive, and the places included in those researches were highly diverse (houses, parks, tourist places, etc.). Operationally, in this research, micro-attachment is defined as a home attachment; meso-attachment is limited as neighborhood cohesion, workplace/campus attachment, as well as city attachment; and macro-attachment is limited as national identity.

It is hoped that the results of this research can be used to give information about the attachment object which has the greatest contribution to pro-environmental behavior so that psychosocial intervention can be prioritized and focused on it.

This research also involves variable of prejudice against environmental activists as predictors of pro-environmental behavior. It is based on the fact about the collapse of Greenpeace credibility in the sight of some Indonesians (Hermawan, 2012). If response generalization occurs, the collapse of credibility will effect on negative attitude or prejudice against the pro-environmental activists in general. According to Yale Attitude Change Approach, the persuasive message conveyed by those who have no credibility will run into the decrease of effectiveness (Aronson, Wilson, \& Akert, 2007).

\subsection{Literature Review}

Bioclimatic concept and design strategies in buildings involve many disciplines, including human physiology, climatology and building physics (Olgyay, 1963). The principle behind the bioclimatic design is the understanding of the climatic factors of a site by analysing the influence of microclimate (solar radiation, sunshine, temperature, humidity, rainfall, wind velocity and direction) (Hyde, 2000). It is followed by a comparative analysis in assessing the climate data concerning thermal comfort and ends with the selection of climate responsive 
modification concept. This concept adopts a passive mode that includes built-form configuration and orientation, enclosure and facade design, daylight, natural ventilation, landscaping, etc., to optimise internal comfort conditions while reducing energy demands for electricity (Yeang, 2008; Zr \& Mochtar, 2013).

$\mathrm{POE}$ is defined as a process of evaluating buildings in a systematic and rigorous manner to indicate the satisfaction and comfort level needed by occupants as lessons learned to identify problems in indoor environments (Khalil \& Husin, 2009). Among plausible benefits of conducting the POE include applying design skills more effectively, improving commissioning process, user requirements and management procedures, providing knowledge of design guides and regulatory processes, and targeting of refurbishment (Whyte \&Gann, 2001). POE begins with planning, conducting and applying phase, can be done on three levels: indicative, investigative and diagnostic levels (Preiser, 1995). Each level has different techniques that can be assessed and utilized to the time frame, budget, manpower, aim and objectives that are to be achieved (Bordass \& Leaman, 2005). There is audit (using quantitative technical assessments), discussions (use discursive techniques such as workshops and interviews), questionnaires (methods that are used to adapt the procurement process to incorporate feedback in an organized manner) and packages (using probes). A critical evaluation using questionnaire system can be achieved when only most relevant issues are highlighted, rather than attempting to analyse everything and risk an overload of data (Niroumand et al., 2013).

There are four significant barriers to POE implementation: ownership, liability, lack of knowledge and progress (Hadjri \& Crozier, 2009). Riley et al. (2010) also highlighted culture as a barrier to POE process where the occupants may feel that moving into a new working environment is disruptive. Without any constructive database, the comparison cannot be carried out to identify the level of achievement (Mier et al., 2009). Therefore, the findings contribute to the establishment of a valuable database and systematic data collection system, particularly for residential college building in the tropics. It is inevitable that by providing opportunities for the improvement of building performance and the relationships of users' behaviour, able to provide a significant role in Malaysia's construction industry (Khalil et al., 2012).

\subsection{Methodology}

\section{Participants and design}

The participants of this research are 262 urban young adults (121 males, 141 females; Mage $=30.09$ years old, $S D_{\text {age }}=9.82$ years) who are citizens of Jakarta and its surrounding areas (Bogor, Depok, Tangerang, and Bekasi). As much as $42.4 \%$ of them claim as the Jakartan originally while $57.6 \%$ of them are immigrant. The average of the staying period of the participants in the city they lived at this time is 17.03 years; with a standard deviation of 13.54 years.

The predictive correlational research design is used in this study. Multiple linear regression analysis is carried out to estimate the relationship between home attachment, neighborhood 
cohesion, workplace/campus attachment, city attachment, and national identity as predictor variables, and general pro-environmental behavior as the criterion variable.

\section{Materials and procedures}

Participants were given psychological scales in Indonesian to measure the predictor and criterion variables. The scales were presented with six response choices, ranging from Strongly Disagree (scored 1) to Strongly Agree (scored 6). Preliminary items tryout and evaluation of the scales for their validity and reliability were conducted in advance. Try out data were obtained from 30 urban young adults (12 males, 18 females).

Psychological scales used to measure pro-environmental behavior is adapted from proenvironmental behavior scale and environmental activism scale which are constructed by Dono, Webb, and Richardson (2010) as well as Videras, Owen, Conover, and Wu (2012). This scale consists of 15 items. The examples of the items are as follows: (1) "In the last 12 months, I avoid buying products from a company that I know may be harming the environment"; (2) "In the last 12 months, I signed and/or circulated a petition (offline / online) in support of protecting the environment". The analysis of reliability and validity show indices of Cronbach's Alpha 0.820 and corrected item-total correlations ranged from 0.314 to 0.643 , by deleting four items.

Scale for measuring home attachment is adapted from McAndrew (1998). This scale consists of 10 items. The examples of the items are as follows: (1) "I could not be happy living in one place for the rest of my life"; (2) "There is not much of a future for me in my home" (unfavorable item, reversely scored). The analysis of reliability and validity show indices of Cronbach's Alpha 0.6 and corrected item-total correlations ranged from 0.30 to 0.511 , by deleting six items.

Scale for measuring neighborhood cohesion is adapted from Buckner (1988). This scale is developed by the author and consists of 22 items. The examples of the items are as follows: (1) "I feel like I belong to this neighborhood"; (2) "I think I agree with most people in my neighborhood about what is valuable in life"; The analysis of reliability and validity show indices of Cronbach's Alpha 0.857 and corrected item-total correlations ranged from 0.340 to 0.691 , by deleting 8 items.

Scale for measuring workplace/campus attachment is adapted from Rioux (2011). This scale consists of 7 items. The examples of the items are as follows: (1) "I am attached to my workplace/campus"; (2) "This workplace/campus is a part of my inner-self"; and (3) "After a holiday, I am happy to go back to my workplace/campus". The analysis of reliability and validity show indices of Cronbach's Alpha 0.798 and corrected item-total correlations ranged from 0.585 to 0.724 , by deleting four items.

Scale for measuring attachment to the city (city attachment) is adapted from Scannell and Gifford (2010) as well as Knez (2005). This scale consists of 22 items. The examples of the items are as follows: (1) "When I am away I miss the community of this city"; (2) "This city is special to me"; and (3) "I feel good when I am in this part of the city." The analysis of reliability and validity show indices of Cronbach's Alpha 0.902 and corrected item-total correlations ranged from 0.330 to 0.778 , by deleting four items. 
Scale for measuring national identity is adapted from Lilli and Diehl (1999). This scale consists of 20 items. The examples of the items are as follows: (1) "I often feel I'm a useless member of the nation I belong to" (unfavorable item); (2) "I feel good about the nation I belong to." The analysis of reliability and validity show indices of Cronbach's Alpha 0.825 and corrected item-total correlations ranged from 0.404 to 0.660 , by deleting 11 items.

Scale for measuring prejudice toward pro-environmental activist is individually constructed by the author. This scale consists of 12 items. The examples of the items are as follows: (1) "Pro-environmental activist has gone too far caring political issues beyond the environment issues"; (2) "The data related to the environment which is used by proenvironmental activists are inaccurate." The analysis of reliability and validity show indices of Cronbach's Alpha 0.860 and corrected item-total correlations ranged from 0.352 to 0.744 , without any aborted items.

\subsection{Results and Discussions}

Multiple linear regression analysis shows that $R^{2}=0.182, F(6,261)=9.452, p=0.000$. It is found that workplace/campus attachment $(\beta=0.275, p<0.05)$, city attachment $(\beta=0.153$, $p<0.05)$, and neighborhood cohesion $(\beta=0.130, p<0.05)$ significantly positively predict general pro-environmental behavior (see Table 1). Meanwhile, home attachment $(\beta=-0.106$, $p>0.05)$, national identity $(\beta=-0.078, p>0.05)$, and prejudice toward pro-environmental activists $(\beta=0.011, p>0.05)$ cannot predict pro-environmental behavior.

Table 1: Multiple linear regression analysis predicting general pro-environmental behavior $(n=262)$

\begin{tabular}{lllll}
\hline Variable & $B$ & $S E B$ & $\beta$ & $p$ \\
\hline $\begin{array}{l}\text { Home } \\
\text { attachment }\end{array}$ & -0.281 & 0.161 & -0.106 & 0.083 \\
$\begin{array}{l}\text { Neighborhood } \\
\text { cohesion }\end{array}$ & 0.109 & 0.055 & 0.130 & 0.048 \\
$\begin{array}{l}\text { Workplace/ca } \\
\text { mpus } \\
\text { attachment }\end{array}$ & 0.827 & 0.191 & 0.275 & 0.000 \\
$\begin{array}{l}\text { City attachment0.097 } \\
\text { National } \\
\text { identity }\end{array}$ & 0.0413 & 0.091 & 0.153 & \\
$\begin{array}{l}\text { Prejudice } \\
\text { toward pro- } \\
\text { environmental } \\
\text { activists }\end{array}$ & 0.009 & -0.078 & 0.027 \\
\hline
\end{tabular}

Note. $R^{2}=0.182 ; S E=$ standard error

This research reveals that home attachment is not able to predict pro-environmental behavior. Home or "interactions within the household" may influence the behavior of children 
and adults (positive correlation), especially through the parent's pro-environmental values and beliefs and their environmentally significant behaviors (Grønhøj \& Thøgersen, 2012; Torres-Antonini \& Vatralova, 2012). However, there is also an ironic fact, "the family home as the locus of consumption looks set fair to cause the ultimate disruption, destruction of the earth as the home of humanity" (negative correlation) (Taylor, as cited in Reid, Sutton, \& Hunter, 2010); hence scores from participants' diminished each other, so no correlation appeared.

In the macro level, national identity does not influence the general proenvironmental behavior. It indicates that people's trust in the state officials decreases as stated by Tarmizi A. Karim, the Acehnese Acting Governor (Bakri, 2012). By using theories of persuasion (Aronson, Wilson, \& Akert, 2007), it is clear that the distrust toward state officers leads to the ineffectiveness of each of messages delivered by the government including a message about pro-environmental behavior.

This research also finds that attachment in the wider scope instead of home attachment; that is workplace/campus attachment, city attachment, and neighborhood cohesion, affects pro-environmental behavior.

To describe the influence of neighborhood cohesion toward pro-environmental behavior, Reid, Sutton, and Hunter (2010) use normative pro-environmental behavior concept. Their definition seems to involve upward social comparison mechanism, in which particular pro-environmental behavior might become the mainstream across a local neighborhood, and it leads a sense of obligation to do the same behavior. There is a popular metaphor; "The grass is always greener on the other side of the fence". It symbolically shows the influence of neighborhood toward the individual behavior. This metaphor usually has a negative connotation, but this research shows us that this metaphor can also be empowered to increase positive pro-environment behavior with the terms based on appreciative cohesion, not from envious perspective.

However, the finding of workplace/campus and city attachments superiorities above the neighborhood cohesion in influencing pro-environmental behavior (indicated by stronger $\beta$-value) is reasonable. This is because of the nature of urban youth life currently which emphasizes the patterns of communication instead of co-presence in which "virtual sites connect face-to-face groups with nodes of dissemination, such as social media and topical discussion boards" (Fine, 2012, p. 169). Virtual representation concerning city and workplace/campus is more vivid on the websites of social networking rather than a representation of neighboring. The representations build and sharpen the common identity, shared meaning, collective culture, social capital, social relations, and even collective action in the networking. Social network media among neighborhood, such as Nextdoor.com in America, has not been popular in Indonesia. We need to consider the fact that most of the urban youth spend most of their time outside the house and in virtual networking in which their identities are honed there.

Compared with neighborhood, city has clearer limits (Lewicka, 2010). It describes why city attachment has a stronger relationship than neighborhood cohesion with proenvironmental behavior. It is in accordance with McKenzie statement (as cited in Matthews, 2008 , p. 257), "probably no other term is used so loosely or with such changing content as 
the term neighborhood, and very few concepts are more difficult to define." Because of that, Matthews' (2008) suggestion, for the researcher to ripen the integration of theoretical and conceptual models of the neighborhood from across the social sciences, can be justified. In the relation with this research, it is suggested that the clarity of neighborhood concept may reduce the fluctuation power of relation between neighborhood cohesion and proenvironmental behavior.

For the urban youths in Indonesia, the prejudice against environmental activists does not simply decrease their pro-environmental behavior. It shows that environmental activists are not seen as significant others or valuable reference group for them. Also, it should be recognized that there are some contradictions, either in the community (internally) or in inter-community of pro-environmental activists. For example, Patrick Moore, the founder of Greenpeace, who had left Greenpeace even strongly criticized Greenpeace that is considered exploiting Japan's nuclear crisis to frighten and to make the government of Ontario to not to build a nuclear reactor again there (Pusat Diseminasi Iptek Nuklir Badan Tenaga Nuklir Nasional, n.d). According to Moore, Greenpeace is more interested in frightening people by a technique such as religion doctrine, which is built on conviction, not fact or evidence.

\subsection{Conclusion}

The contribution of this research is its effort to include the five attachment objects all together which are considered as a "place." A place conceptualized here is not only a natural physical appearance but also ecological systems where communities exist and share ideas, feelings and activities. The places are chosen since they are in which people live 24 hours a day. From this research, it is found that workplace/campus attachment, city attachment, and neighborhood cohesion can predict pro-environmental behavior.

There are some evidence that intervention program for pro-environmental behavior will be successful if this program interact with norm salience, either manipulated explicitly (e.g. Laurens, 2012) or implicitly (e.g. Fritsche, Jonas, Kayser, \& Koranyi, 2010). This research recommends that to increase pro-environmental behavior for urban youth; we should give more attention and build intervention toward attachment and norm salience in the context of (1) workplace/campus, (2) city, and (3) neighborhood. The intervention is also can be done by campaigning, such as "If you destroy your environment, then you will hurt your workplace I campus, city, and neighborhood", or "If you do something good for your environment, then you will make your people of workplace / campus, city, and neighborhood happy".

\section{References}

Aronson, E., Wilson, T. D., \& Akert, R. M. (2007). Social psychology (6th ed.). New Jersey: Pearson Education.

Bakri. (2012, April 26). Gubernur lantik Pj Bupati Aceh Barat. Retrieved from http://aceh.tribunnews.com/2012/04/26/gubernur-lantik-pj-bupati-aceh-barat 
Buckner, J. C. (1988). The development of an instrument to measure neighborhood cohesion. American Journal of Community Psychology, 16, 771-791.

Dallago, L., Perkins, D. D., Santinello, M., Boyce, W., Molcho, M., \& Morgan, A. (2009). Adolescent place attachment, social capital, and perceived safety: A comparison of 13 countries. American Journal of Community Psychology, 44, 148-160.

Dono, J., Webb, J., \& Richardson, B. (2010). The relationship between environmental activism, pro-environmental behaviour and social identity. Journal of Environmental Psychology, 30, 178-186.

Fine, G. A. (2012). Group culture and the interaction order: Local sociology on the meso-Level. Annual Review of Sociology, 38. 159-179.

Francis, P. (2002). Social capital at the World Bank: Strategic and operational implications of the concept. Retrieved from http://siteresources.worldbank.org/INTRANETSOCIALDEVELOPMENT/2145781112888617281/20549275/Francis4.pdf

Fritsche, I., Jonas, E., Kayser, D. N., \& Koranyi, N. (2010). Existential threat and compliance with pro-environmental norms. Journal of Environmental Psychology, 30, 67-79.

Grønhøj, A., \& Thøgersen, J. (2012). Action speaks louder than words: The effect of personal attitudes and family norms on adolescents' pro-environmental behaviour. Journal of Economic Psychology, 33, 292-302.

Hermawan, B. (2012, 1 November). Kantor Greenpeace dilemparibangkaitikus. Retrieved from http://m.inilah.com/read/detail/1922355/kantor-greenpeace-dilempari-bangkai-tikus

Hidalgo, M. C., \& Hernández, B. (2001). Place attachment: Conceptual and empirical questions. Journal of Environmental Psychology, 21, 273-281.

Knez, I. (2005). Attachment and identity as related to a place and its perceived climate. Journal of Environmental Psychology, 25(2), 207-218.

Lewicka, M. (2010). What makes neighborhood different from home and city? Effects of place scale on place attachment. Journal of Environmental Psychology, 30, 35-51.

Lilli, W., \& Diehl, M. (1999). Measuring national identity. Mannheimer Zentrum für Europäische Sozialforschung Nr. 10.

Matthews, S. A. (2008). The salience of neighborhood: Some lessons from sociology. American Journal of Preventive Medicine, 34(3), 257-259.

McAndrew, F. T. (1998). The measurement of 'rootedness' and the prediction of attachment to home-towns in college students. Journal of Environmental Psychology, 18, 409-417.

Pusat Diseminasi Iptek Nuklir Badan Tenaga Nuklir Nasional. (n.d.). Patrick Moore: Pendiri Greenpeace mendukungnuklir. Retrieved from http://www.batan.go.id/pdin/publikasi/file/buku\%20patrick\%20moore.pdf

Reid, L., Sutton, P., \& Hunter, C. (2010). Theorizing the meso level: The household as a crucible of proenvironmental behaviour. Progress in Human Geography, 34(3), 309-327.

Rioux, L. (2011). Workplace attachment and request for professional transfer: Study on a population of French employees. Bulletin of the Transilvania University of Brasov, Series VII : Social Sciences and Law, 4(2), 91-96.

Scannell, L., \& Gifford, R. (2010). The relations between natural and civic place attachment and pro-environmental 
Abraham, J., \& Rufaedah, A. / Asian Journal of Behavioural Studies (AjBeS), 3(10) Mar / Apr 2018 (p.117-125)

behavior. Journal of Environmental Psychology, 30, 289-297.

Torres-Antonini, M., \& Vatralova, Z. (2012). Greener child care: Parents' pro-environmental values, beliefs, behaviors, and knowledge and their child. Journal of Interior Design, 37(2), 1-18

Videras, J., Owen, A. L., Conover, E., \& Wu, S. (2012). The influence of social relationships on pro-environment behaviors. Journal of Environmental Economics and Management, 63, 35-50.

Winter, D. D. N., \& Koger, S. M. (2004). The psychology of environmental problems. New Jersey: Lawrence Erlbaum Associates. 